\title{
A STUDY OF TEN CHILDREN AFTER TREATMENT WITH STREPTOMYCIN FOR TUBERCULOUS MENINGITIS
}

\author{
BY \\ JOHN LORBER, M.B., B.Chir., M.R.C.P. \\ (From the Department of Child Health, University of Sheffield)
}

Following the discovery of streptomycin by Waksman (1944) and his colleagues, great hopes were entertained that its use in cases of tuberculosis, and especially of tuberculous meningitis, would be followed by results equally dramatic and good as those with penicillin in pyogenic infection in general and the pyogenic meningitides in particular. These hopes were engendered by the excellent experimental results in guinea-pigs achieved by Feldman and Hinshaw (1944), but the first few reports of cases of tuberculous meningitis treated by streptomycin were so discouraging that opinion swung the other way. Of Hinshaw's (1946) first four living cases after relatively short periods of follow-up, one was blind, one deaf, one ataxic, and one was still being treated. Cooke's (1946) patient who recovered was left with 'nervous and mental changes.' Krafchik's (1946) case was apparently well after a very short follow-up.

The general impression was expressed in the following annotation in the "British Medical Journal ' late in 1946:

-The results of American and limited British tests of streptomycin in tuberculous meningitis have, in particular, been far less encouraging than was originally hoped; there seems to be a very real risk that, even if the infection is controlled (as has only very rarely happened) the patient will usually be left mentally deficient, deaf, blind, or otherwise a hopeless invalid.'

Later publications (Alperin and Toomey, 1948; American Trudeau Society, 1947 and 1949; Applebaum and Halkin, 1947; Bunn, 1948; Cathie, 1949; Choremis, 1948; Debré et al., 1948; Decourt, 1948; Dolivo and Rossi, 1948; Dowling, 1949; Dubois, 1948 ; 'Lancet,' 1948a and 1948b ; McDermott, 1947; Mann, 1948; Medical Research Council, 1948; Mordasini, 1948; Nau, and Wenzler, 1948; and Rubie and Mohun, 1949) produce an over-all impression that when tuberculous meningitis is treated with streptomycin most patients die, and that of the minority who survive a considerable number are deaf or paralysed, and others are mentally abnormal. Smith et al. (1948), and Lincoln and Kirmse (1949) on the contrary, point out that recovered cases have not been left badly crippled either physically or mentally.

\section{Material of Present Study}

Between September, 1947, and July, 1948, twenty-seven patients suffering from tuberculous meningitis were treated in the Streptomycin Unit of the Department of Child Health, University of Sheffield, under the direction of Professor R. S. Illingworth. Of these sixteen died and one is alive, but is still having treatment. The remaining ten cases are the material of the present study, and they satisfy the following criteria.

Each patient has been followed up for a minimum of ten months, from the beginning of treatment to the end of May, 1949. (See table 1.)

TABLE 1

\begin{tabular}{|c|c|c|c|c|}
\hline AGES & $\mathbf{N}$ & $\begin{array}{l}\text { ADMISSIC } \\
\text { FOI }\end{array}$ & $\begin{array}{l}\text { AND LE } \\
\text { OW-UP }\end{array}$ & TH OF \\
\hline \multirow[b]{2}{*}{ Case } & \multirow[b]{2}{*}{ Sex } & \multirow[b]{2}{*}{$\begin{array}{l}\text { Age on } \\
\text { Admission } \\
\text { in years }\end{array}$} & \multicolumn{2}{|c|}{$\begin{array}{l}\text { Length of Follow-up } \\
\text { in Months }\end{array}$} \\
\hline & & & $\begin{array}{l}\text { Beginning of } \\
\text { treatment to } \\
\text { May } 31,1949\end{array}$ & $\begin{array}{c}\text { End of } \\
\text { treatment to } \\
\mathrm{M} \text { ay } 31,1949\end{array}$ \\
\hline $\begin{array}{l}\text { (L.M.) } \\
\text { (P.F.) } \\
\text { (J.H.) } \\
\text { (K.E.) } \\
\text { (E.R.) } \\
\text { (G.H.) } \\
\text { (G.H.) } \\
\text { (G.R.) } \\
\text { (D.C.) } \\
\text { (C.W.) } \\
\text { (J.D.) }\end{array}$ & $\begin{array}{l}\mathbf{M} . \\
\mathbf{M} . \\
\mathbf{F} . \\
\mathbf{F} . \\
\mathbf{M} . \\
\mathbf{F} . \\
\mathbf{M} . \\
\mathbf{M} . \\
\mathbf{F} . \\
\mathbf{F} .\end{array}$ & $\begin{array}{l}6 \frac{6}{12} \\
1 \frac{3}{12} \\
5 \frac{\frac{6}{12}}{6} \\
6 \frac{8}{12} \\
\frac{111}{12} \\
8_{12}^{\frac{2}{2}} \\
3 \frac{8}{12} \\
1 \frac{2}{12} \\
5 \frac{6}{12} \\
8\end{array}$ & $\begin{array}{l}20 \\
19 \\
19 \\
17 \\
15 \\
14 \\
14 \\
13 \\
12 \\
10\end{array}$ & $\begin{array}{r}16 \\
12 \\
8 \\
4 \\
8 \\
10 \\
6 \\
7 \\
6 \\
4\end{array}$ \\
\hline
\end{tabular}

The cerebrospinal fluid is normal in every case. Tubercle bacilli were found in each case. Organisms of the human type were isolated from all patients though not necessarily from the cerebrospinal fluid in patients with miliary tuberculosis as well as meningitis.

Each child is now at home.

All the children are reporting monthly to a special follow-up clinic. 
In six of these ten cases miliary tuberculosis was also.present at the beginning of treatment, but the patients are now radiologically clear of miliary lesions. None of the ten patients was unconscious before or during treatment and none had convulsions. All had intrathecal treatment. In the only case in this series (G.H.) in which air encephalography was performed (eight months after treatment started) the ventricular system was found to be normal.

Three of these children were under two years of age on admission.

\section{Method of Investigation}

The physical state of the children is assessed by a monthly routine examination, which includes weighing, x-ray scrutiny of the chest and, less often, investigation of the cerebrospinal fluid.

Their behaviour-is noted and enquiries are made about their behaviour at home. Where practicable some have been visited and observed in their homes.

Intellectual achievements are also noted, and in all cases of school age reports are obtained from the school about their previous behaviour and mental development. In addition, every case undergoes psychometric testing some time after the conclusion of treatment and where necessary the tests are repeated at a later date.

In children over five the Terman-Merrill ' $L$ ' scale (a modified Stanford-Binet scale), and in children of pre-school age the Gesell test with some Terman-Merrill items, were used for measuring intelligence. In one case (K.E.) a special set of tests for the deaf was selected (Collins-Drever battery). Table 2 shows the method employed in each case and the results.

Wherever possible the general family background is also reviewed to place each case in a better perspective.

\section{Interpretation of Results of Psychometric Tests}

Although these tests were designed to eliminate as much as possible the influence of experience and education, nevertheless the absence of normal home life and schooling for up to a year or more must to some extent adversely influence the results. Further, it was not always possible to gain the full co-operation of all the children, especially toddlers, partly because of their recent memory of injections and other therapeutic procedures.

The delay in development, which was marked in the younger age groups, can be largely ascribed to their prolonged stay in hospital. That this is so is shown by the very rapid improvement in their achievements after only a short period at home. The acquisition of speech and sphincter control is particularly difficult in hospital.

These factors must be taken into consideration in the assessment of the results obtained, but when the tests are repeated after a longer follow-up they will be eliminated.

\section{Case Reports}

Case 1. L.M., aged eight years and one month, an only child, is a sturdy, well-built boy in perfect physical health.

TABLE 2

METHODS AND RESULTS OF INTELLIGENCE TESTS

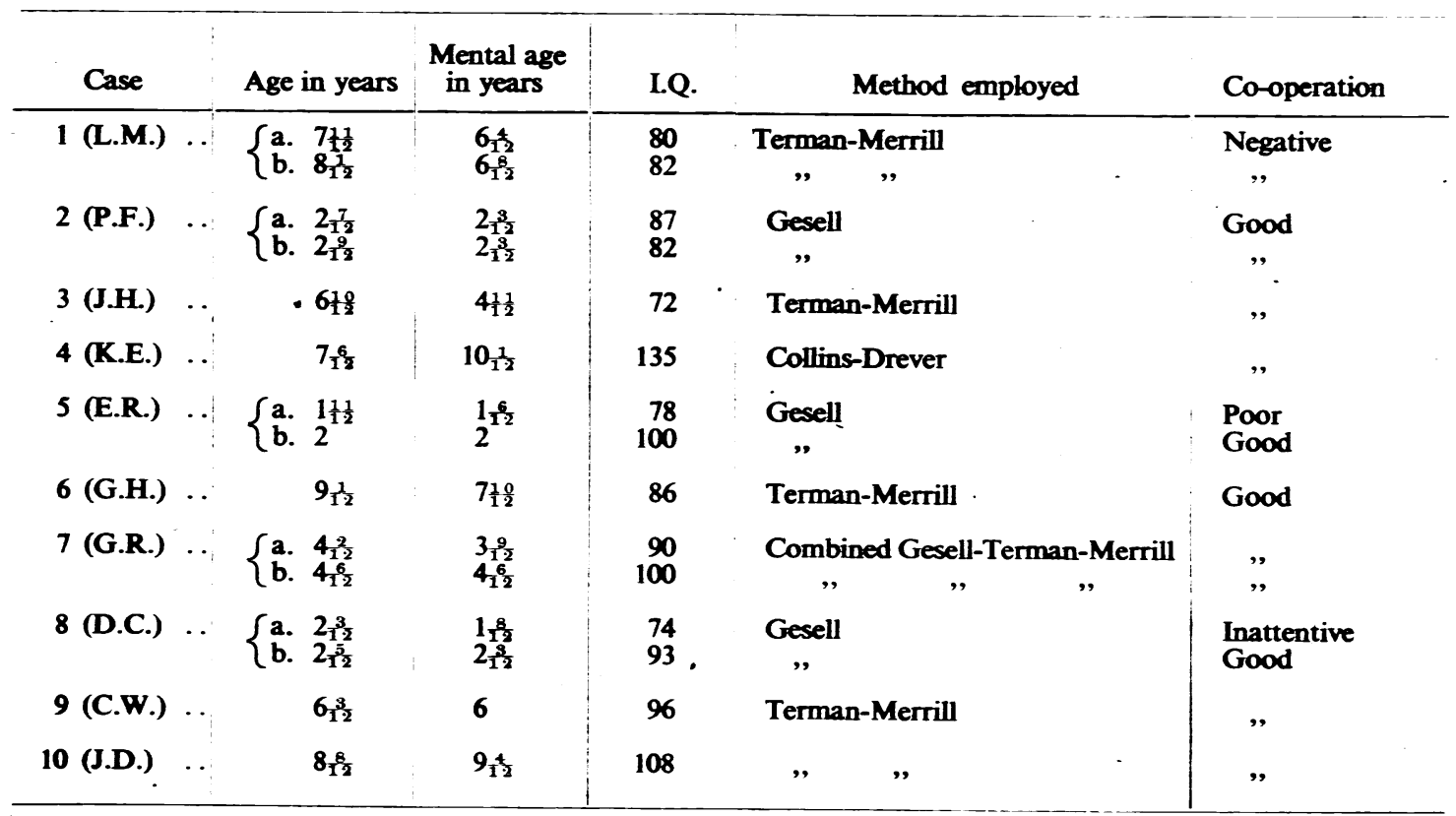


He was always a shy, taciturn child, lacking in confidence. He had little to say while he was in hospital but was always well behaved as he is now. He is attending school, but unfortunately he derives less benefit from this than he should, as he is placed in a form with boys of his own age. Because he missed a whole year he cannot catch up with the others, and this makes him still more diffident. This behaviour was reflected in the results of his two intelligence tests performed within two months. His I.Q., 80 and 82 at the two tests respectively, was felt to be an underestimate of his true ability and his various failures were probably due not so much to inability to perform some of the test items, as to a negative attitude to the test situation.

Case 2 P.F., aged two years and nine months, is the younger of two boys. He is in fine physical health. The last radiograph of his chest shows a healed fibrotic lesion at one apex at the site of his original primary focus.

His parents are sensible, ordinary people, except that the mother suffers from attacks of hysteria.

The boy is active, interested in everything, friendlyand happy, giving much pleasure to his parents and friends. Although he was very backward on his discharge from hospital, he is picking up rapidly and can do most things a child of his age should do. According to his parents he is more intelligent than his elder brother.

He was very co-operative at his first psychometric test, performed three months after his discharge home. There was some scatter, but his general level was between 24 and 30/12, and his I.Q., 87. The second test was performed two months later. His mother was present at the beginning of the test, but had to be removed on account of an attack of hysteria. The child, nevertheless, co-operated quite well, but showed no change in the previous level attained.

Case 3. J.H., a girl aged six years and ten months, comes from a very dull family and is the first of two children. Her mother in particular is a woman of very low intelligence, completely unreliable, and emotionally unstable.

This child is in very good health, is usually active and happy, but her behaviour is very much like her mother's as she is emotional and sometimes difficult to control at home. In this respect she is no different from what she has always been and she never did well at school.

Her intelligence behind a bright facade is obviously low. At her psychometric test she co-operated well, but her I.Q. was only 72 . Though she had virtually no schooling it was not felt in this case that lack of experience of normal life materially affected the test result though this factor cannot be ruled out entirely.

Case 4. K.E., a girl of seven and a half years, is an only child of bright, intelligent parents, and before her illness was always very forward.

Physically she is perfectly fit, but is unfortunately deaf. She had one relapse of meningitis, but following a second course of treatment the cerebrospinal fluid has now been normal for six months.

Emotionally she is labile, and, while most of the time she is charming, she has temper tantrums. This is probably due to the newly acquired deafneas and the difficult situations to which this gives rise. That her illness is not likely to have diminished her mental capacity was shown at her psychometric test (Collins-Drever battery) which gave a figure of 135. This test was performed a month before discharge from the convalescent home. She is being given lessons in lip-reading and now that she can understand better what other people say, the temper tantrums have decreased.

Case 5. E.R., a boy aged two years, is an only child of an intelligent mother and a less intelligent father, situated in very poor circumstances. He is a very friendly, happy boy, not afraid of strangers at home, although he was shy and reluctant to co-operate in tests at the hospital. At his first psychometric test at the hospital, a year after his admission, his I.Q. was 78 only. This was felt to be an underestimate of his real developiment. The next test was therefore performed at his own home, and here he showed himself to be fully equal to the mental standard of his chronological age, and his I.Q. was 100. In the bulk of the test items there was little scatter, but in a few respects a wide divergence from the average was noted in each direction.

Case 6. G.H., a girl aged nine years and one month, is one of four children in a very poor home. The father deserted the family, and the mother, though trying to do her best for the family, is of low intelligence. This child was retarded before her illness. For example, she could not walk unaided until sixteen months.

She is in good physical health and is perfectly normal emotionally though her interests are rather limited. Her psychometric measurement gave an I.Q. of 86 which is a true mirror of her present mental ability.

Case 7. G.R., a boy of three years and five months, is the second child of an average father and an intelligent mother. The mother and several members of the family on her side are extremely highly strung people. Her father committed suicide in a paroxysm of anxiety, and the mother herself appears to be suffering from an acute anxiety state. In spite of that, she is a good and careful mother.

The child shows constant activity, is alert and keen, always at the centre of attraction, and a general favourite. In most respects he knows much more now than children of his age, especially in memorizing figures and difficult names. At his first psychometric test before his discharge from hospital he showed considerable fluctuation in achievement, surpassing his age in memory tests but falling short in picture identification and other items where his lack of experience hindered him. His I.Q. was only 90 on this occasion.

Three months later he was re-tested and this time 
he again proved to be well above the average in certain items, though below it in tests involving motor functions. With this scatter above and below his chronological age his I.Q. came to. 100 . There seems to be little doubt that he will do better in time.

Case 8. D.C., a boy of one year and two months, comes from an average family and has one elder brother. He developed normally until his illness. He is now well but still has a large opacity in his lung which remained practically unchanged during treatment.

The child is active and playful, but was obviously much below the general level of mental development for his age at the time of the first psychometric test, performed just before his discharge. Co-operation in the test was patchy, but his I.Q. of 74 was probably accurate. He was particularly defective in speech and toilet habits. At a re-test, two months later at his own home, he showed considerable improvement. He was interested and co-operative. By now he was ' dry,' could speak in three-word sentences, knew a nursery rhyme, and was in general of a higher intellectual development than his elder brother of three and a half who was tested at the same time. His present I.Q. is 93.

Case 9. C.W., aged six years and three months, is an only daughter of average parents. Before her illness she was a very bright child and was thought to be exceptional by her mother. Although she only attended school for four weeks, her teacher remembers her as a child of great intelligence and of a happy and quiet disposition. In hospital she was always very quiet.

She is now physically perfectly fit. She co-operated well in her psychometric test, performed just before her discharge from huspital, and her I.Q. was 96. According to her mother, she is not quite so bright as she was before her illness. The school report corroborates the mother's estimate of her previous mental level, which though fully up to average now, may have fallen.

Case 10. J.D., eight years and eight months old, is the younger of two girls and has bright intelligent parents. She is in perfect physical health and has a most attractive personality. She is interested in everything around her and is pleasant to all. Although rather nervous at first during her intelligence test, she did well and her I.Q. of 108 may be higher after a period at home.

Of these ten children, five boys and five girls, comprising all the cases of a consecutive series who are alive after the completion of their treatment with streptomycin for tuberculous meningitis, nine have no physical disabilities attributable either to the disease or to its treatment. One child is deaf, possibly permanently, although a short time ago she could hear a very loud noise for the first time.

In no case have the parents noted any change in the behaviour of the child following the disease and its treatment. There is only one mild behaviour problem (case 3).

The range of the intelligence quotients of these children, tested between eight and eighteen months after the beginning of treatment, and in no case less than two. months after the end of treatment, is between I.Q. 72 and 135. This is within the normal range of variation in the general population. The number of cases is far too small for statistical analysis. Smith et al. (1948) obtained similar results in their recovered cases.

These results do not confirm the many pessimistic opinions about the outcome of tuberculous meningitis. It is true that serious sequelae may result from the disease or its treatment but in our experience they are infrequent.

\section{Summary}

The physical and mental state and the emotional pattern of ten children successfully treated with streptomycin for tuberculous meningitis have been analysed. All the children are now at home and have been followed up for at least ten months from the beginning of treatment, and for four to sixteen and a half months after the treatment completed by the end of May, 1949.

All the children are in good physical health and are normal mentally. There is no evidence that the illness has caused any difference in their general behaviour. The intelligence quotients are within the normal range of variation.

The only neurological after-effect is deafness in one case.

All the children were alive and well at the end of July, 1949, after a minimum observation period of one year from the beginning of treatment.

These cases were treated under the Streptomycin Investigation Scheme of the Ministry of Health.

Thanks are due to Mr. N. E. Whilde, school educational psychologist, Sheffield, for his collaboration with the psychometric tests in the school-age children, to Sir Weldon Dalrymple-Champneys, Bart., for his permission to publish, and to Sister Farrow and her nurses for their part in achieving these results.

I should especially like to thank Professor R. S. Illingworth for his constant help, encouragement, and criticism.

\section{REFERENCES}

Alperin, L., and Toomey, J. A. (1948). J. Pediat., 33, 74. American Trudeau Society (1947). Amer. Rev. Tuberc., 56. 477. (1949). Ibid., 59, 106.

Annotation (1946). Brit. med. J., $2,906$.

Appelbaum, E. and Halkin, C. (1947). J. Amer. med. Assoc., 135, 153.

Bunn, P. A. (1948). Amer. J. med. Sci., 216, 286.

Cairns, H., and Taylor, M. (1949). Proc. R. Soc. Med., 42, 155 . 
Cathie, I. A. B. (1949). Lancet, 1, 441.

Choremis, K., Zervos, N., Constantinides, V., and Pantazis, S. (1948). Lancet, 2, 595.

Cooke, R. E., Dunphy, D. L., and Blake, F. G. (1946). Yale J. Biol. Med., 18, 221.

Debré, R., Thiefry, S., and Brissaud, H. E. (1948). La Streptomycine appliquée au traitement de la méningite tuberculeuse et de la tuberculose miliaire chez l'enfant. Paris. 182-189.

Decourt, J., Guillemin, J., Canivet, J., Sibertin-Blanc, J., Jupeau, M., Villiaumey, J., and Chevance, L. G. (1948). Pr. Med., 56, 128.

Dolivo, G., and Rossi, E. (1948). Streptomycin und Tuberkulose, edited by Fanconi, G., and Löffler, W. Basel.

Dowling, H. F., Sweet, L. K., Hirsh, H. L., and Lepper, M. H. (1949). J. Amer. med. Assoc., 139, 755.

Dubois, R., Linz, R., Leschanowski, H., Schlesser, R., and Wattiez, R. (1948). Acta clin. belg., 3, 1 .

Editorial (1947). Amer. Rev. Tuberc., 56, 442.

(1948a). Lancet, 1, 217.

(1948b). Ibid., 1, 291.
Feldman, W. H., and Hinshaw, H. C. (1944). Proc. Mayo Clin., 19, 593.

Hinshaw, H. C., Feldman, W. H., and Pfuetze, K. H. (1946). J. Amer. med. Ass., 132, 778.

Lincoln, E. M., and Kirmse, T. W. (1949). Lancet, 1, 767.

Mann, T. P. (1948). Proc. R. Soc. Med., 41, 671.

McDermott, W., Muschenheim, C., Hadley, S. J., Bunn, P. A., and Gorman, R. V. (1947). Ann. Intern. Med., 27, 769.

Mordasini, E. (1948). Schweiz. med. Wschr., 78, 605.

Medical Research Council (1948). Lancet, 1, 582.

Nau, O. S., and Wenzler, F. J. (1948). J. Pediat., 3, 410.

Rubie, J., and Mohun, A. F. (1949). Brit. med. J., 1, 338.

Schatz, A., Bugie, E., and Wakeman, S. A. (1944). Proc. Soc. exp. Biol., 55, 66.

Smith, H. V., Vollum, R. L., and Cairns, H. (1948). Lancet, 1, 627. 